\title{
Hydrothermal synthesis of Mo-V mixed oxides possessing several crystalline phases and their performance in the catalytic oxydehydration of glycerol to acrylic acid
}

\author{
Letícia F. Rasteiro, Luiz H. Vieira, Luiz G. Possato, Sandra H. Pulcinelli, Celso V. Santilli, \\ Leandro Martins*
}

Instituto de Química, UNESP_Universidade Estadual Paulista, Rua Prof. Francisco Degni 55, CEP 14800-900 Araraquara, SP, Brazil

\section{A R T I C L E I N F O}

\section{Keywords:}

Glycerol oxydehydration

Acrylic acid

Molybdenum-vanadium mixed oxides

Hydrothermal synthesis

Bifunctional catalysts

\begin{abstract}
A B S T R A C T
The one-step oxydehydration of glycerol to acrylic acid over molybdenum and vanadium mixed oxides was investigated. The Mo-V oxide catalysts were prepared by a simple hydrothermal method under different synthesis and calcination atmospheres and were characterized by in situ XRD, TPD- $\mathrm{NH}_{3}, \mathrm{~N}_{2}$ adsorption/ desorption, X-ray absorption near vanadium K-edge spectroscopy and thermogravimetry. The catalytic performance of the samples at different temperatures (290, 320 and $350{ }^{\circ} \mathrm{C}$ ) and under different gas flow compositions $\left(20 \% \mathrm{O}_{2}\right.$ in $\mathrm{N}_{2}, 100 \% \mathrm{O}_{2}$, or $100 \% \mathrm{~N}_{2}$ ) revealed that the arrangement of the crystallographic structures of the active phases directly influenced the catalytic performance. It was found that the catalysts heattreated in oxidizing atmosphere gave superior catalytic results comparing with the catalysts heat-treated in inert atmosphere due to the equilibrium between the crystalline phases $\mathrm{MoVO}_{5}$ and $\mathrm{Mo}_{4.65} \mathrm{~V}_{0.35} \mathrm{O}_{14}$ that contains $\mathrm{V}^{+4}$ and $\mathrm{V}^{+5}$. Catalytic oxydehydration at $320{ }^{\circ} \mathrm{C}$ under a flow of $100 \% \mathrm{O}_{2}$ gave the best performance, achieving selectivity of $33.5 \%$ towards acrylic acid and $100 \%$ conversion of glycerol.
\end{abstract}

\section{Introduction}

The depletion of fossil fuel reserves and the need for cleaner energy sources have intensified the search for alternative fuels that are cleaner and less harmful to the environment [1-3]. Biodiesel has proved to be a good option and its production involves a simple process that essentially occurs by the transesterification of oils and fats derived from plant and animal sources with short chain alcohols, typically methanol, in the presence of catalysts [4,5]. Glycerol is a major co-product of this process, equivalent to $10 \mathrm{wt} . \%$ of the biodiesel production. The use of biodiesel increases every year, and it is forecast that in 2020 biodiesel production will be nearly 36.9 million metric tons, 10 million metric tons more than the current production. Therefore, for the success of the biodiesel production chain, it is essential to find pathways to use or consume glycerol $[6,7]$. Due to its non-toxicity, glycerol has many commercial applications, such as in the manufacture of medicines, foods, beverages, and textiles [8]. Beyond these applications, other pathways are being studied at the laboratory scale, and this is the case of glycerol dehydration and oxidation to produce value-added products such as acrolein and acrylic acid [7].

Acrylic acid is an important industrial bulk chemical used mainly to produce superabsorbent polymers, due to its high liquid absorbance capacity [9]. It can be produced by glycerol dehydration to form acrolein, followed by oxidation of acrolein to acrylic acid, by means of a two-step process occurring in a single or double catalytic bed $[10,11]$. In 2011 Dubois et al. [12,13] patented a method for producing acrylic acid from glycerol (US 7,910,771 B2 and US 8,212,070 B2), but using a double bed reactor with two catalysts. Although presenting a high selectivity, a high catalyst mass in relation to the glycerol feed is used. Comparing the productivity of acrylic acid per gram of catalyst per hour, a bifunctional catalyst is more valuable.

In order to perform the glycerol conversion to acrylic acid using a single catalysts, this catalyst has to be bifunctional, because acid and redox active sites are needed for the dehydration and oxidation steps, respectively [10-21]. The use of a bifunctional catalyst to convert glycerol not only has engineering and economic advantages, but also minimizes the use of petrochemical resources as raw materials, hence providing a competitive route for the production of acrylic acid [12-14].

Approximately $75 \%$ of applications in the chemical industry use mixed oxide catalysts [22], which have been studied for many gas phase reactions including ethane oxidation [23,24], ethane oxidative

\footnotetext{
* Corresponding author.

E-mail address: leandro@iq.unesp.br (L. Martins).
} 
dehydrogenation [25], selective oxidation of light alkanes [26], propane oxidation [27,28], glycerol dehydration to acrolein [29], and more recently the conversion of glycerol to acrylic acid $[10,20,30]$. Some works have also reported the transformation of glycerol to acrolein by a liquid phase reaction, giving a great catalytic activity [31,32]. Although materials such as $\mathrm{W}-\mathrm{Mo}-\mathrm{V}$ oxides [17,18], W-V oxides [20,30], $\mathrm{Mo}_{3} \mathrm{VO}_{\mathrm{x}} / \mathrm{H}_{4} \mathrm{SiW}_{12} \mathrm{O}_{40} / \mathrm{Al}_{2} \mathrm{O}_{3}$ [16], and $\mathrm{W}$-V-Nb oxides [14] have shown high capacity to convert acrolein to acrylic acid, only a few studies have reported good selectivity $[14,33,34]$, Omata et al. [34] was one of the few that achieved a high selectivity to acrylic acid using $\mathrm{W}-\mathrm{V}-\mathrm{Nb}$ mixed oxides (59.2\%), but with the modification of the surface with phosphoric acid. One of the first studies of mixed oxides containing vanadium and molybdenum catalysts occurred in 1978, when Thorsteinyon et al. [35] produced a mixed oxide of vanadium, molybdenum, and niobium to perform the oxidative dehydrogenation of ethane. More recently, $\mathrm{Mo}_{\mathrm{x}} \mathrm{V}_{\mathrm{y}} \mathrm{O}_{\mathrm{z}}$ catalysts have gained attention, because these catalysts not only possess the acid sites that are necessary for the dehydration of glycerol, but also present oxidative potential, which is essential for the oxidation step [17,31-33]. Furthermore, only a few studies have used molybdenum and vanadium as the only metals in catalysts for the oxydehydration of glycerol to acrylic acid $[19,30,36]$, so there is still great potential for exploration of the use of $\mathrm{Mo}_{\mathrm{x}} \mathrm{V}_{\mathrm{y}} \mathrm{O}_{\mathrm{z}}$ catalysts in this catalytic reaction.

In this study, we synthesized mixed Mo-V oxides possessing several crystalline phases and assessed their performance in the catalytic oxydehydration of glycerol to acrylic acid. The influence of the synthesis procedure on formation of the active catalyst components and, consequently, on the oxydehydration reaction, was explored using a combination of several techniques: in situ X-ray diffraction (XRD), ammonia temperature programmed desorption $\left(\mathrm{NH}_{3}-\mathrm{TPD}\right)$, elemental chemical analysis, thermogravimetry, and X-ray absorption near vanadium K-edge spectroscopy.

\section{Experimental section}

\subsection{Catalyst preparation}

The synthesis of the mixed oxides was performed based on a hydrothermal method described previously by Katou et al. [27]. The main difference was the control of the synthesis atmosphere by the addition of $\mathrm{N}_{2}$ or $\mathrm{O}_{2}$. In a typical synthesis procedure, $0.84 \mathrm{~g}$ of $\mathrm{VOSO}_{4}$ was dissolved in $13.9 \mathrm{~mL}$ of distilled water. Separately, $1.28 \mathrm{~g}$ of $\left(\mathrm{NH}_{4}\right)_{6} \mathrm{Mo}_{7} \mathrm{O}_{24} \cdot 4 \mathrm{H}_{2} \mathrm{O}$ was dissolved in $13.9 \mathrm{~mL}$ of distilled water. The two solutions were mixed and stirred for $10 \mathrm{~min}$ at $25^{\circ} \mathrm{C}$, resulting in a solution with $\mathrm{pH} 2.8$ and a Mo/(Mo $+\mathrm{V})$ molar ratio of 0.60 , which corresponded to the optimal catalyst composition to give the highest conversion of glycerol to acrylic acid, as tested in a previous study [36]. Afterwards, the solution was transferred to a $50 \mathrm{~mL}$ Teflon vessel contained in a stainless steel autoclave reactor. The solution occupied approximately $70 \%$ of the capacity of the vessel. The reactor was hermetically closed and then purged with the required gas $\left(\mathrm{N}_{2}\right.$ or $\left.\mathrm{O}_{2}\right)$ in successive cycles controlled using a valve. Finally, the reactor was pressurized to 6 bar with the required gas. The reactor was placed in a glycerol bath heated at $160{ }^{\circ} \mathrm{C}$ for $48 \mathrm{~h}$ under static conditions. The solid formed was separated by centrifugation and dried at $60{ }^{\circ} \mathrm{C}$ for $12 \mathrm{~h}$. The resulting catalyst precursors synthesized in oxygen and nitrogen atmospheres were denoted $\mathrm{MoV}-\mathrm{O}_{2}$ and $\mathrm{MoV}-\mathrm{N}_{2}$, respectively.

The final stage in preparation of the catalysts was calcination of the MoV- $\mathrm{O}_{2}$ and MoV- $\mathrm{N}_{2}$ precursors in a fixed bed reactor at $500{ }^{\circ} \mathrm{C}$ for $2 \mathrm{~h}$ under a flow of pure $\mathrm{O}_{2}$ or pure $\mathrm{N}_{2}$. The four different samples obtained were named according to the synthesis and calcination (in parentheses) atmospheres as MoV- $\mathrm{O}_{2}\left(\mathrm{O}_{2}\right)$, MoV- $\mathrm{O}_{2}\left(\mathrm{~N}_{2}\right)$, MoV- $\mathrm{N}_{2}\left(\mathrm{O}_{2}\right)$, and MoV$\mathrm{N}_{2}\left(\mathrm{~N}_{2}\right)$. For the purpose of comparison, pure $\mathrm{MoO}_{3}$ and $\mathrm{V}_{2} \mathrm{O}_{5}$ oxides were prepared by calcination of the $\left(\mathrm{NH}_{4}\right)_{6} \mathrm{Mo}_{7} \mathrm{O}_{24} \cdot 4 \mathrm{H}_{2} \mathrm{O}$ and $\mathrm{VOSO}_{4}$ precursors.

\subsection{Characterization techniques}

The evolution of the crystalline phases during heating of the MoV$\mathrm{N}_{2}$ and $\mathrm{MoV}-\mathrm{O}_{2}$ samples was analyzed by in situ X-ray diffraction at the XPD beamline of the Brazilian Synchrotron Light Laboratory (LNLS), using a synchrotron radiation wavelength of $0.16522 \mathrm{~nm}$. The thermal treatment was performed from room temperature up to $500{ }^{\circ} \mathrm{C}$, at a heating rate of $10{ }^{\circ} \mathrm{C} / \mathrm{min}$, in an atmosphere of $5 \% \mathrm{O}_{2}$ or $100 \% \mathrm{~N}_{2}$. Data were collected in a $2 \theta$ range from $7^{\circ}$ to $60^{\circ}$.

The crystalline phases formed in the spent catalysts were analyzed by conventional X-ray diffraction (XRD), using a Rigaku Miniflex 600 diffractometer with $\mathrm{CuK \alpha}$ radiation $(0.15418 \mathrm{~nm})$ selected with a curved graphite monochromator. Data were collected in the $2 \theta$ range from $5^{\circ}$ to $60^{\circ}$, with a scan step of $0.02^{\circ}$ and counting time of $1 \mathrm{~s}$. All the crystalline phases of the samples were identified with Crystallographica Search Match software and were then quantified by the Rietveld refinement method using TOPAS ${ }^{\circ} 4.2$ software.

The amounts of $\mathrm{V}$ and Mo present in the catalysts were determined by chemical analysis of the synthesis solutions (mother liquors) using an Optima 8000 ICP-OES spectrometer.

Thermogravimetric analysis (TGA) of the spent catalysts was conducted under an atmosphere of $100 \% \mathrm{O}_{2}$ at a flow rate of $100 \mathrm{~mL} / \mathrm{min}$, using an SDT Q600 TGA/DSC thermobalance, with heating in the range $30-600{ }^{\circ} \mathrm{C}$ at a rate of $10{ }^{\circ} \mathrm{C} / \mathrm{min}$.

$\mathrm{X}$-ray absorption spectroscopy (XAS) measurements at the vanadium K-edge were recorded in transmission mode at the XAFS1 beamline of the Brazilian Synchrotron Light Laboratory (LNLS). The XAFS1 beamline was equipped with a monochromator (Si (111) for vanadium), operated in Bragg mode, for selection of the chosen range of Xray energy. The monochromator was calibrated by setting the first inflection point at the K-edge spectrum of a metallic foil standard ( $5465 \mathrm{eV}$ for vanadium). The powdered samples were pressed into pellets, whose thickness was chosen so that the absorption jump at the edge was close to 1 . Analysis of the XAS data using the Athena graphical interface software enabled speciation of the vanadium by means of linear combinations (LC) of the spectra (from -20 to $120 \mathrm{eV}$ around the edge), using three merged spectra in order to improve the signal-tonoise ratio. The references used for quantitative analyses were $\mathrm{V}_{2} \mathrm{O}_{3}$, $\mathrm{V}_{2} \mathrm{O}_{4}, \mathrm{~V}_{2} \mathrm{O}_{5}$, and metallic vanadium foil.

The acid sites of the fresh and spent catalysts were measured by temperature programmed desorption of ammonia (TPD- $\mathrm{NH}_{3}$ ). In these experiments, a mass of $250 \mathrm{mg}$ of sample was placed under a He flow $(60 \mathrm{~mL} / \mathrm{min})$ at $300^{\circ} \mathrm{C}$ for $1 \mathrm{~h}$, followed by cooling to $100{ }^{\circ} \mathrm{C}$. At this temperature, the sample was exposed to a $60 \mathrm{~mL} / \mathrm{min}$ flow of $1 \% \mathrm{NH}_{3}$ in He for $1 \mathrm{~h}$. The excess and physically adsorbed $\mathrm{NH}_{3}$ were then purged at $100{ }^{\circ} \mathrm{C}$ under a flow of He during $60 \mathrm{~min}$. Finally, ammonia was desorbed in a He flow of $60 \mathrm{~mL} / \mathrm{min}$, with heating from 100 to $500{ }^{\circ} \mathrm{C}$ at a rate of $10^{\circ} \mathrm{C} / \mathrm{min}$. The amount of ammonia desorbed per gram of sample was calculated from measurements made using a mass spectrometer (PrismaPlus QMG 220, Pfeiffer).

The specific surface areas of the samples were determined by nitrogen sorption measurements performed at liquid nitrogen temperature $\left(-196{ }^{\circ} \mathrm{C}\right)$, with relative pressure interval between 0.001 and 0.998, using a Micrometrics ASAP 2010 system. The samples were pretreated under vacuum $\left(\sim 10 \times 10^{-6} \mathrm{~Pa}\right)$ for $12 \mathrm{~h}$ at $200^{\circ} \mathrm{C}$. The BET method was used to determine the specific surface area $\left(\mathrm{S}_{\mathrm{BET}}\right)$ [37].

\subsection{Catalytic glycerol oxydehydration}

The catalytic reaction was conducted in the gas phase at 290, 320, and $350{ }^{\circ} \mathrm{C}$, under atmospheric pressure, using a fixed bed reactor. Firstly, $200 \mathrm{mg}$ of the calcined catalyst was supported on glass wool placed inside the reactor. The reactor was heated to the reaction temperature under continuous flows $(30 \mathrm{~mL} / \mathrm{min})$ of three different gas compositions $\left(100 \% \mathrm{O}_{2}, 100 \% \mathrm{~N}_{2}\right.$, or $20 \% \mathrm{O}_{2}$ in $\left.80 \% \mathrm{~N}_{2}\right)$, and was maintained at this temperature for $15 \mathrm{~min}$ before initiating the reaction. 
A solution containing $10 \mathrm{wt} . \%$ of glycerol (Sigma-Aldrich, 99\%) in water was fed to the reactor at a flow rate of $0.05 \mathrm{~mL} / \mathrm{min}$. The exact gas composition was glycerol/oxygen/water $=2 / 28 / 70(\% \mathrm{~mol})$ when using $100 \% \mathrm{O}_{2}$, glycerol/nitrogen/water $=2 / 28 / 70(\% \mathrm{~mol})$ when using $100 \% \quad \mathrm{~N}_{2}$ and glycerol/oxygen/nitrogen/water $=2 / 5 / 23 / 70$ ( $\%$ mol) when using air composition. The products were condensed in a gas-liquid separator kept at $1{ }^{\circ} \mathrm{C}$ and aliquots were withdrawn every $1 \mathrm{~h}$. A previous test was performed to confirm full recovery of the condensable products outflowing from the reactor, by injecting a solution of $10 \mathrm{wt} . \%$ acetaldehyde (b.p. of $20{ }^{\circ} \mathrm{C}$ ) in water into the reactor and determining the mass balance in the gas-liquid separator. The products were quantified using a gas chromatograph (Shimadzu GC-2014) equipped with a capillary column (RTX-1, $30 \mathrm{~m}, 0.32 \mathrm{~mm}$, $1 \mu \mathrm{m}$ ) and a flame ionization detector (FID). As part of the products was converted to $\mathrm{CO}$ and $\mathrm{CO}_{2}$, a known mass of $n$-butanol was added as an internal standard before each injection and compared with a calibration curve of the products. The glycerol conversion $\left(\mathrm{X}_{\mathrm{g} 1}\right)$ and products selectivity $\left(S_{i}\right)$ were calculated according to Eq. (1) and (2), respectively.

$X_{g l}(\%)=\frac{n_{g l}^{\text {input }}-n_{g l}^{\text {output }}}{n_{g l}^{\text {input }}} \times 100$

$S_{i}(\%)=\frac{n_{i}}{n_{g l} l^{\text {input }}-n_{g l}{ }^{\text {output }}} \times \frac{z_{i}}{z_{g l}}$

where $n_{g l}^{\text {input }}$ and $n_{g l}{ }^{\text {output }}$ are the molar flow rates of glycerol in the input and in the output ( $\mathrm{mol} / \mathrm{min}), n_{\mathrm{i}}$ is the molar flow of product $i, z_{g l}$ is the number of carbon atoms in the glycerol molecule, and $z_{i}$ is the number of carbon atoms in the products [38]. The carbon balance to obtain the selectivity to $\mathrm{CO}_{\mathrm{x}}$ compounds was calculated from the ratio of the molar flow of products and unconverted glycerol leaving the reactor and the molar flow of glycerol fed to the reactor.

\section{Results}

\subsection{Characteristics of the catalysts}

The hydrothermal synthesis procedure enabled a very high solid yield to be obtained, with consequently a high incorporation of molybdenum and vanadium atoms in the solid (Table 1 ). The synthesis performed in the presence of $\mathrm{O}_{2}$ was much more effective, since almost $100 \%$ of the transition metal atoms were incorporated in the solid. Elemental chemical analysis of the dried samples showed no significant incorporation of any other element, indicating that the $\mathrm{N}$ and $\mathrm{S}$ elements present in the precursors remained in the mother liquor as ionic pairs of $\mathrm{NH}_{4}{ }^{+}$and $\mathrm{SO}_{4}{ }^{2-}$. Therefore, the precipitate formed was free from the precursor salts and was composed of mixed oxides of molybdenum and vanadium.

The mixed oxides formed in the hydrothermal synthesis were further calcined in $\mathrm{N}_{2}$ or $\mathrm{O}_{2}$ atmospheres, and the changes of the crystalline phases during the heat treatment were followed using in situ X-ray diffraction measurements (Fig. 1). The crystalline phases of the catalysts produced in the hydrothermal synthesis or after the calcination procedure were highly dependent on the atmosphere used. Table 2 lists the crystalline structures that were detected during the various steps of the study, together with the corresponding JCPDS powder

Table 1

Hydrothermal synthesis of MoV mixed oxides in $\mathrm{N}_{2}$ and $\mathrm{O}_{2}$ atmospheres, and the solid yields calculated after chemical analysis of the mother liquors.

\begin{tabular}{|c|c|c|c|c|c|}
\hline \multirow[t]{2}{*}{ Sample } & \multirow[t]{2}{*}{$\mathrm{pH}_{\text {final }}$} & \multirow{2}{*}{$\begin{array}{l}\text { Solid yield } \\
(\%)\end{array}$} & \multicolumn{2}{|c|}{ Degree of incorporation } & \multirow{2}{*}{$\begin{array}{l}\mathrm{Mo} /(\mathrm{Mo}+\mathrm{V}) \text { molar } \\
\text { ratio in the solid }\end{array}$} \\
\hline & & & $\%$ Mo & $\% \mathrm{~V}$ & \\
\hline $\mathrm{MoV}-\mathrm{N}_{2}$ & 2.5 & 72.4 & 70.6 & 85.2 & 0.55 \\
\hline $\mathrm{MoV}-\mathrm{O}_{2}$ & 1.8 & 98.1 & 98.8 & 97.3 & 0.60 \\
\hline
\end{tabular}

diffraction files (PDF). Fig. 2 shows the phases present in the assynthesized samples and in the materials calcined in oxidizing and inert atmospheres. Fig. 3 shows the results of the Rietveld refinement, with a combination of distinct phases found for the samples. The synthesis of the mixed oxides in the presence of $\mathrm{N}_{2}$ resulted in formation of the orthorhombic $\mathrm{Mo}_{3} \mathrm{VO}_{\mathrm{x}}$ phase, which has characteristic peaks at $2 \theta$ of around $9^{\circ}, 24^{\circ}$, and $49^{\circ}$, as reported in other studies [14,25,29,36-40]. In the case of the synthesis in the presence of $\mathrm{O}_{2}$, the X-ray diffraction fingerprint corresponded to three different phases, with predominance $(70 \%)$ of $\mathrm{Mo}_{0.88} \mathrm{~V}_{0.12} \mathrm{O}_{2.94}$. When the syntheses were performed in the presence of $\mathrm{N}_{2}$, due to its non-reactivity, the atmosphere didn't influence the synthesis. However when $\mathrm{O}_{2}$ was used, the oxidative atmosphere influenced in the reaction, that is why almost $70 \%$ of the phase $\mathrm{Mo}_{0.88} \mathrm{~V}_{0.12} \mathrm{O}_{2.94}$ was formed.

When the sample was synthesized in an oxidizing atmosphere and also submitted to an oxidizing atmosphere during the heat treatment, distinct phases were formed, with predominance of the $\mathrm{Mo}_{4.65} \mathrm{~V}_{0.35} \mathrm{O}_{14}$ phase (Fig. 3). There was also a substantial quantity of the $\mathrm{MoV}_{2} \mathrm{O}_{8}$ phase, which was reported by Possato et al. [36] to perform well in the oxydehydration of glycerol. The $\mathrm{MoV}_{2} \mathrm{O}_{8}$ phase was the main phase formed $(80 \%)$ when the MoV-O $\mathrm{O}_{2}$ sample was submitted to an inert atmosphere during the heat treatment.

Highly diverse crystalline phases were also obtained for the MoV-N sample treated under $\mathrm{N}_{2}$ or $\mathrm{O}_{2}$ atmospheres. The heat treatment in an oxidizing atmosphere gave the same phases as found in the MoV-O $\mathrm{O}_{2}\left(\mathrm{O}_{2}\right)$ sample, but in different quantities. There was almost the same amount of the $\mathrm{Mo}_{4.65} \mathrm{~V}_{0.35} \mathrm{O}_{14}$ phase, while the $\mathrm{MoV}_{2} \mathrm{O}_{8}$ phase decreased to around $5 \%$ and the $\mathrm{MoO}_{3}$ phase increased to approximately $50 \%$. According to Liu et al. [16], the use of $\mathrm{MoO}_{3}$ as catalyst in the oxydehydration of glycerol leads to the formation of $\mathrm{CO}$ and $\mathrm{CO}_{2}$, so the catalytic potential of the catalyst is decreased. Formation of the reduced forms of the oxides, $\mathrm{V}_{2} \mathrm{O}_{3}$ (around 90\%) and $\mathrm{MoO}_{2}$, was observed when the MoV- $\mathrm{N}_{2}$ sample was treated in $\mathrm{N}_{2}$. This was the only sample that did not present crystalline phases of the mixed oxides.

The textural characteristics of the calcined catalysts were assessed by means of $\mathrm{N}_{2}$ adsorption-desorption isotherms. Table 3 summarizes the BET surface area results for the Mo- $\mathrm{V}$ mixed oxides, with values in the range $7.4-12.8 \mathrm{~m}^{2} / \mathrm{g}$. The surface areas of $\mathrm{MoO}_{3}$ and $\mathrm{V}_{2} \mathrm{O}_{5}$ were in the range $0.5-7.6 \mathrm{~m}^{2} / \mathrm{g}$. The surface area of the mixed oxides was low due to the absence of a porous network, as confirmed by the nitrogen adsorption isotherm profiles (Fig. S1).

The TPD- $\mathrm{NH}_{3}$ profiles of the catalysts are shown in Fig. S2. Table 3 provides the quantification of the acid sites, which were classified according to three strengths: weak $\left(100-200{ }^{\circ} \mathrm{C}\right)$, medium $\left(200-300{ }^{\circ} \mathrm{C}\right)$, and strong $\left(>300{ }^{\circ} \mathrm{C}\right)$. The $\mathrm{MoO}_{3}$ presented a high quantity of acid sites, while the amount decreased dramatically in the mixed oxides, reaching a similar value as $\mathrm{V}_{2} \mathrm{O}_{5}$. The majority of the acid sites in the Mo-V oxides possessed weak and medium strengths. The samples calcined under nitrogen had slightly higher quantities of acid sites, although the differences were not significant.

\subsection{Catalytic results}

Glycerol oxydehydration performed under different conditions enabled elucidation of the effects of the conditions employed in the hydrothermal syntheses and for calcination of the molybdenum and vanadium mixed oxides on the acrylic acid production. The mixed oxides presented superior performance, compared to the pure $\mathrm{V}_{2} \mathrm{O}_{5}$ and $\mathrm{MoO}_{3}$ oxides. However, before discussing the results in terms of the active phases that contributed to the conversion of glycerol and the reaction conditions that maximized production of acrylic acid, there are several issues that need to be considered:

(a) It is quite possible that the samples contained amounts of amorphous phases of molybdenum and vanadium oxides. For example, Fig. 3 indicates that the MoV- $\mathrm{N}_{2}\left(\mathrm{~N}_{2}\right)$ sample contained more than 


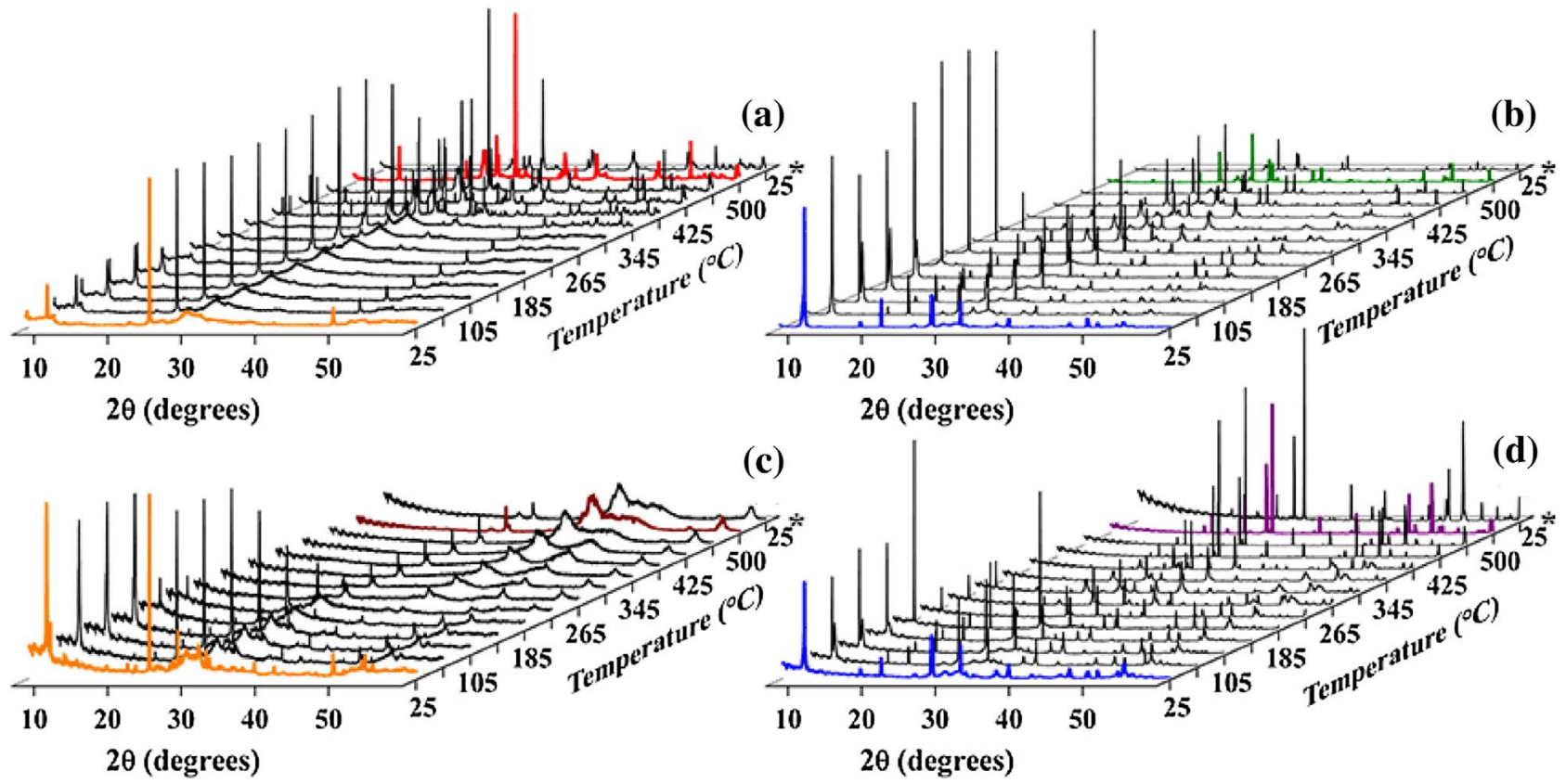

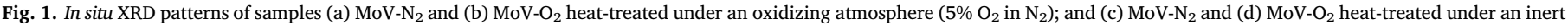
atmosphere $\left(100 \% \mathrm{~N}_{2}\right)$. *Cooled sample.

$80 \%$ crystalline $\mathrm{V}_{2} \mathrm{O}_{3}$, while the chemical analysis revealed that this sample had a Mo/(Mo $+\mathrm{V})$ molar ratio of 0.55 (Table 1$)$. The activity of the amorphous phases in this sample is described in the discussion of the catalytic tests.

(b) The formation of several phases of Mo-V oxides can lead to interfacial surfaces that create a unique reactivity. In order to elucidate this surface phenomenon, sophisticated techniques, in combination with theoretical studies, are needed to reveal the configuration and structure/morphology of the surface, as well as the composition of adsorbed species [42].

(c) The synthesis of pure-phase samples was attempted in order to correlate the catalytic performance individually, but this proved to be unfeasible due to the probable formation of $\mathrm{V}_{2} \mathrm{O}_{5}$ and $\mathrm{MoO}_{3}$ as products of decomposition of the mixed oxides.

Firstly, in the catalytic tests of glycerol oxydehydration (Scheme 1), the MoV- $\mathrm{O}_{2}\left(\mathrm{O}_{2}\right)$ sample was submitted to three different temperatures $\left(290,320\right.$, and $\left.350{ }^{\circ} \mathrm{C}\right)$ in a $6 \mathrm{~h}$ reaction, using a gas flow of $20 \% \mathrm{O}_{2}$ in $\mathrm{N}_{2}$, in order to identify the best conditions for conversion of glycerol to acrylic acid. The differences for each temperature can be seen in Fig. S3 in terms of yield to acrylic acid during the reactions, the error in the measurements are also shown. The most effective temperature was
$320{ }^{\circ} \mathrm{C}$. These results could be explained by the fact that in the temperature of $290{ }^{\circ} \mathrm{C}$ the acrylic acid molecules are more adsorbed on the surface of the catalyst that resulted in an additional oxidation to form COx compounds, justifying the decrease in acrylic acid formation (Fig. S3). The increase of the temperature to $320^{\circ} \mathrm{C}$ aided in the desorption of acrylic acid molecules from the surface of the catalyst. This temperature seems to be ideal for this system, as the temperature is increased to $350^{\circ} \mathrm{C}$ part of the glycerol is decomposed to $\mathrm{CO}_{\mathrm{X}}$ before dehydration to acrolein.

Fig. 4 compares the catalytic activities of the samples of the mixed oxides of molybdenum and vanadium at $320^{\circ} \mathrm{C}$, during the first hour. The catalysts showed a selectivity to $\mathrm{CO}_{\mathrm{x}}$ in a range between 59.2$73.9 \%$ and the lowest selectivities belong to the catalysts heat-treated in oxygen. These materials are quite oxidative so is expected that they present a greater amount of $\mathrm{CO}_{\mathrm{x}}$. The $\mathrm{MoV}-\mathrm{O}_{2}\left(\mathrm{O}_{2}\right)$ sample showed the best performance in converting glycerol to acrylic acid, with the lowest formation of $\mathrm{CO}$ and $\mathrm{CO}_{2}$. As a general tendency, the MoV-N $\mathrm{N}_{2}\left(\mathrm{O}_{2}\right)$ and MoV- $\mathrm{O}_{2}\left(\mathrm{O}_{2}\right)$ catalysts calcined in an oxygen atmosphere provided better selectivity towards acrylic acid and lower selectivity towards $\mathrm{CO}_{\mathrm{x}}$, while the MoV- $\mathrm{N}_{2}\left(\mathrm{~N}_{2}\right)$ and $\mathrm{MoV}-\mathrm{O}_{2}\left(\mathrm{~N}_{2}\right)$ samples calcined in nitrogen exhibited similar selectivity towards acrylic acid as the pure oxides.

Table 2

Crystalline phases and stoichiometric oxidation states of the vanadium and molybdenum oxides.

\begin{tabular}{|c|c|c|c|c|c|c|}
\hline \multirow[t]{2}{*}{ Crystalline compounds } & \multirow[t]{2}{*}{ JCPDS PDF } & \multirow[t]{2}{*}{ Source } & \multirow[t]{2}{*}{ Temperature $\left({ }^{\circ} \mathrm{C}\right)$} & \multirow[t]{2}{*}{ Atmosphere } & \multicolumn{2}{|c|}{ Stoichiometric oxidation state } \\
\hline & & & & & $\mathrm{V}$ & Mo \\
\hline$\left(\mathrm{NH}_{4}\right)_{6} \mathrm{Mo}_{7} \mathrm{O}_{24}$ & $70-0957$ & Precursor & RT & Air & - & 6 \\
\hline $\mathrm{VOSO}_{4}$ & $19-1412$ & Precursor & RT & Air & 4 & - \\
\hline $\mathrm{Mo}_{3} \mathrm{VO}_{\mathrm{x}}$ & - & Synthesis & 160 & $\mathrm{~N}_{2}$ & - & - \\
\hline $\mathrm{MoO}_{3}$ & $89-5108$ & Synthesis/Calcination/Post-reaction & $160 / 500 / 320$ & $\mathrm{O}_{2} / 20 \% \mathrm{O}_{2}$ & - & 6 \\
\hline $\mathrm{MoVO}_{5}$ & 77-0649 & Synthesis/Post-reaction & $160 / 320 / 350$ & $\mathrm{O}_{2} / 20 \% \mathrm{O}_{2}$ & 4 & 6 \\
\hline $\mathrm{Mo}_{0.88} \mathrm{~V}_{0.12} \mathrm{O}_{2.94}$ & $81-2414$ & Synthesis & 160 & $\mathrm{O}_{2}$ & 5 & 6 \\
\hline $\mathrm{Mo}_{4.65} \mathrm{~V}_{0.35} \mathrm{O}_{14}$ & $31-1437$ & Calcination & 500 & $\mathrm{O}_{2}$ & 5.6 & 5.6 \\
\hline $\mathrm{MoV}_{2} \mathrm{O}_{8}$ & $74-0050 / 74-2366$ & Calcination & 500 & $\mathrm{O}_{2}$ & 5 & 6 \\
\hline $\mathrm{MoO}_{2}$ & $32-0671$ & Calcination/Post-reaction & $500 / 350$ & $\mathrm{~N}_{2} / 20 \% \mathrm{O}_{2}$ & - & 4 \\
\hline $\mathrm{V}_{2} \mathrm{O}_{3}$ & $71-0347$ & Calcination & 500 & $\mathrm{~N}_{2}$ & 3 & - \\
\hline $\mathrm{VO}_{2}$ & $82-0661$ & Calcination & 500 & $\mathrm{~N}_{2}$ & 4 & - \\
\hline $\mathrm{V}_{3} \mathrm{O}_{5}$ & $72-0524$ & Calcination & 500 & $\mathrm{~N}_{2}$ & 3.3 & - \\
\hline
\end{tabular}



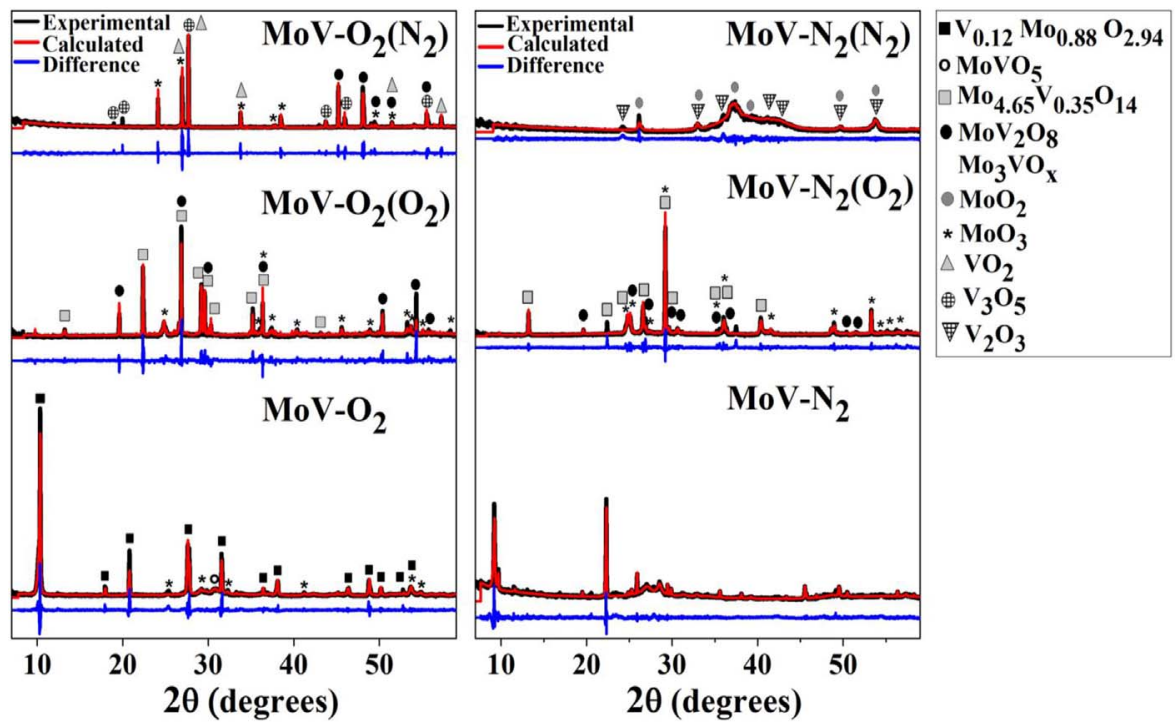

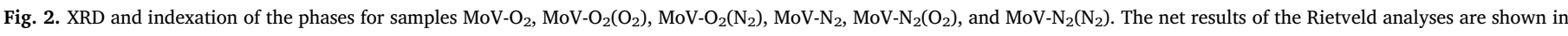

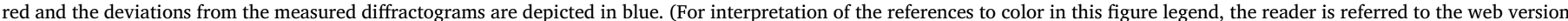
of this article.)

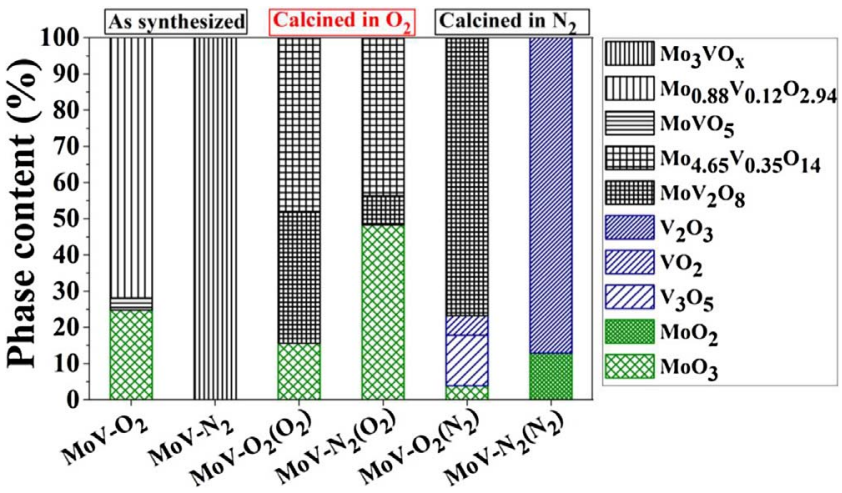

Fig. 3. Crystalline phases found for the mixed oxides of molybdenum and vanadium.

Table 3

BET surface areas and quantification of the acid sites determined by means of $\mathrm{NH}_{3}$-TPD.

\begin{tabular}{|c|c|c|c|c|c|}
\hline \multirow[t]{2}{*}{ Catalyst } & \multicolumn{4}{|c|}{ TPD-NH ${ }_{3}$} & \multirow{2}{*}{$\begin{array}{l}\text { BET } \\
\text { surface } \\
\text { area } \\
\left(\mathrm{m}^{2} \mathrm{~g}^{-1}\right)\end{array}$} \\
\hline & $\begin{array}{l}{ }^{\mathrm{a}} \text { Weak } \\
\left(\mu \mathrm{mol} \mathrm{g}{ }^{-1}\right)\end{array}$ & $\begin{array}{l}{ }^{\mathrm{b}} \text { Medium } \\
\left(\mu \mathrm{mol} \mathrm{g}^{-1}\right)\end{array}$ & $\begin{array}{l}{ }^{\mathrm{c}} \text { Strong } \\
\left(\mu \mathrm{mol} \mathrm{g}^{-1}\right)\end{array}$ & $\begin{array}{l}\text { Total } \\
\left(\mu \mathrm{mol} \mathrm{g}{ }^{-1}\right)\end{array}$ & \\
\hline $\mathrm{MoO}_{3}$ & $51.2(12 \%)$ & $205.0(48 \%)$ & $170.8(40 \%)$ & 427.0 & 0.5 \\
\hline $\mathrm{V}_{2} \mathrm{O}_{5}$ & $6.7(10 \%)$ & $25.5(38 \%)$ & $34.8(52 \%)$ & 67.0 & 7.6 \\
\hline $\mathrm{MoV}-\mathrm{O}_{2}\left(\mathrm{O}_{2}\right)$ & $17.5(45 \%)$ & $19.8(51 \%)$ & $1.6(4 \%)$ & 38.9 & 11.4 \\
\hline MoV-N ${ }_{2}\left(\mathrm{O}_{2}\right)$ & $10.8(44 \%)$ & $9.6(39 \%)$ & $4.4(17 \%)$ & 24.7 & 7.4 \\
\hline MoV- $\mathrm{N}_{2}\left(\mathrm{~N}_{2}\right)$ & $26.4(58 \%)$ & $13.5(30 \%)$ & $5.3(12 \%)$ & 45.2 & 10.8 \\
\hline $\mathrm{MoV}-\mathrm{O}_{2}\left(\mathrm{~N}_{2}\right)$ & $45.4(60 \%)$ & $21.7(29 \%)$ & $8.5(11 \%)$ & 75.6 & 12.8 \\
\hline
\end{tabular}

Acid sites strength: a. Weak $\left(100-200{ }^{\circ} \mathrm{C}\right)$; b. Medium $\left(200-300{ }^{\circ} \mathrm{C}\right)$; c. Strong (> $\left.300{ }^{\circ} \mathrm{C}\right)$.

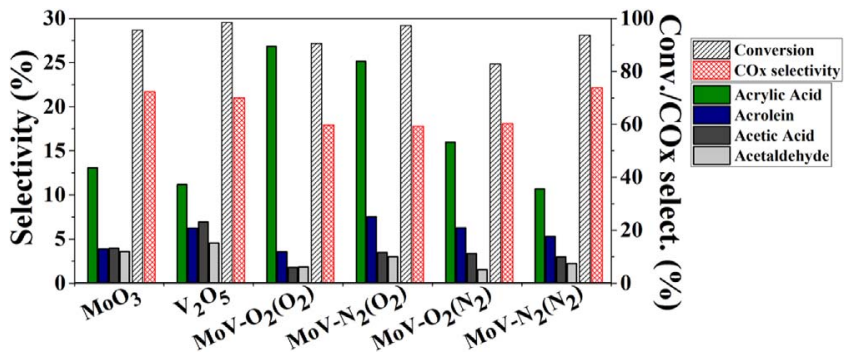

Fig. 4. Catalytic results for a $1 \mathrm{~h}$ reaction at $320{ }^{\circ} \mathrm{C}$ under a flow of $20 \% \mathrm{O}_{2}$ in $\mathrm{N}_{2}$ using the mixed oxides of molybdenum and vanadium.

The influence of the gas flow composition on the reaction was also studied using the MoV- $\mathrm{O}_{2}\left(\mathrm{O}_{2}\right)$ catalyst in a $6 \mathrm{~h}$ reaction at $320^{\circ} \mathrm{C}$ (Fig. 5). For the gas flow composed of $100 \% \mathrm{O}_{2}$, the highest selectivity towards acrylic acid was achieved after $6 \mathrm{~h}$ of reaction. No acrylic acid was formed when $100 \% \mathrm{~N}_{2}$ was used. Lower formation of $\mathrm{CO}_{\mathrm{x}}$ was observed when $100 \% \mathrm{~N}_{2}$ was used, because the absence of an oxidizing atmosphere prevented complete oxidation of the products. However, when $\mathrm{O}_{2}$ was present in the reaction atmosphere, the potential for formation of oxidation products increased, with a higher $\mathrm{O}_{2}$ content resulting in formation of more $\mathrm{CO}_{\mathrm{x}}$.

The importance of feeding $\mathrm{O}_{2}$ is related to the catalytic redox cycle: acrolein is formed on the acid sites and is then promptly oxidized to acrylic acid by reducing a vanadium atom of the oxide lattice; the oxygen vacancy and the vanadium oxidation state are restored by the $\mathrm{O}_{2}$ fed to the reactor. The dynamic reduction and oxidation of vanadium atoms (from $\mathrm{V}^{5+}$ to $\mathrm{V}^{4+}$, and then from $\mathrm{V}^{4+}$ to $\mathrm{V}^{5+}$ ) and the oxidation of acrolein occur according to the Mars-van-Krevelen redox process [43]. The oxidation state of molybdenum $(+6)$ in the lattice of the mixed oxide was invariant, as found in a previous study<smiles>O=C/C=C/[C@@H](O)[C@@H](O)/C=C/C(=O)O</smiles>

Scheme 1. Glycerol oxydehydration: dehydration to acrolein followed by oxidation of acrolein to acrylic acid. 

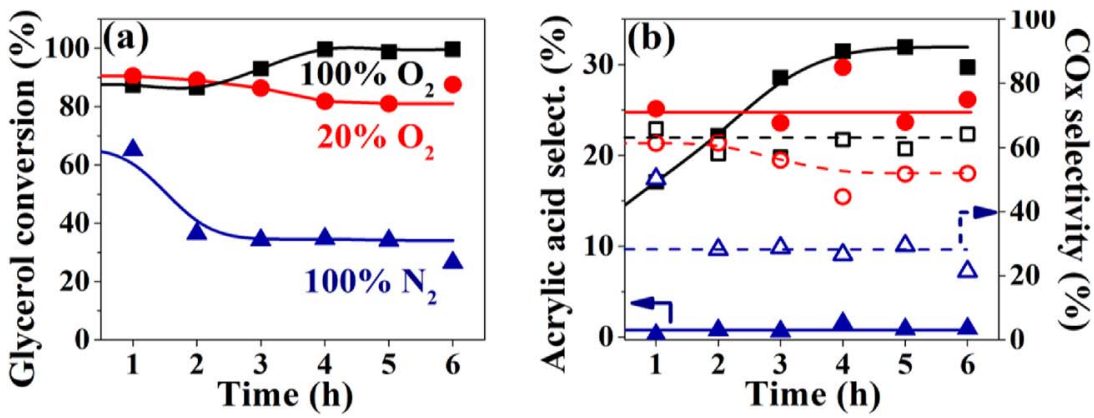

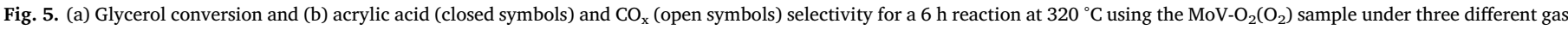
flows $\left(20 \% \mathrm{O}_{2}\right.$ in $\mathrm{N}_{2}, 100 \% \mathrm{O}_{2}$, or $\left.100 \% \mathrm{~N}_{2}\right)$.
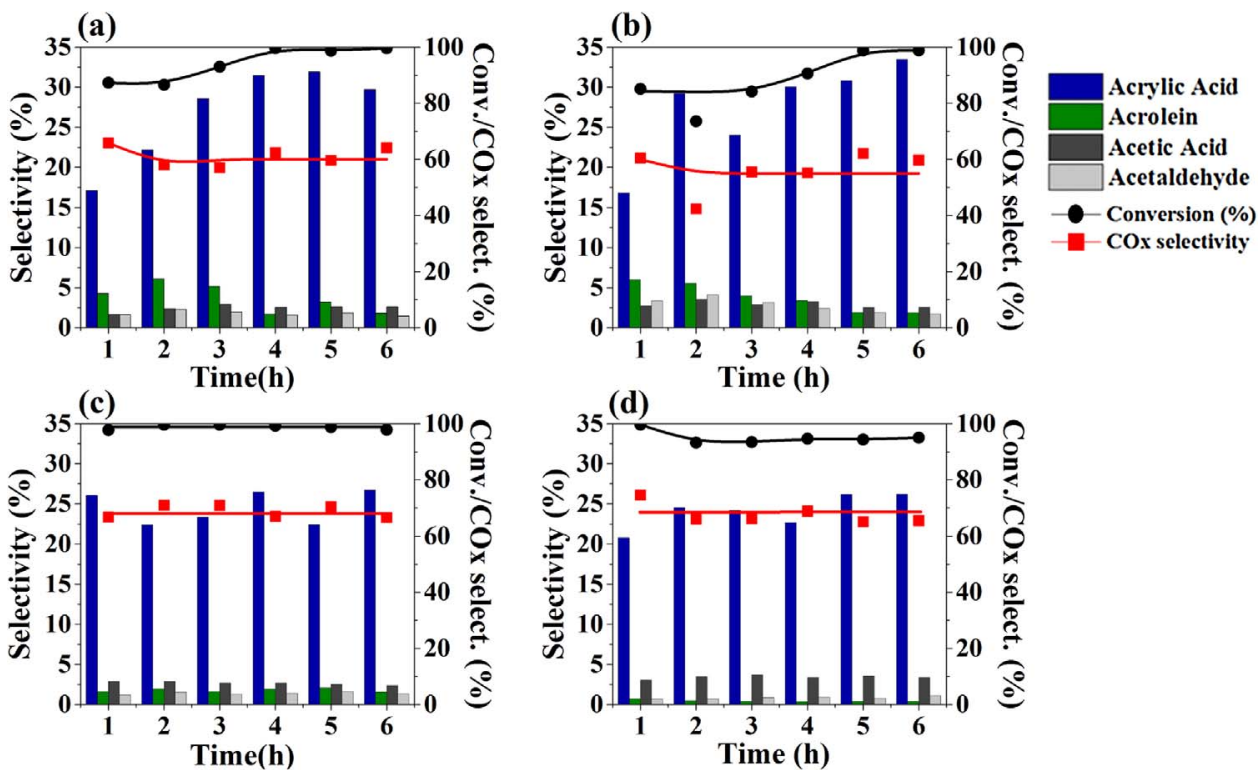

Fig. 6. Catalytic results for a $6 \mathrm{~h}$ reaction at $320{ }^{\circ} \mathrm{C}$ under a $100 \% \mathrm{O}_{2}$ gas flow for the samples (a) $\mathrm{MoV}-\mathrm{O}_{2}\left(\mathrm{O}_{2}\right)$, (b) $\mathrm{MoV}-\mathrm{N}_{2}\left(\mathrm{O}_{2}\right),\left(\right.$ c) $\mathrm{MoV}-\mathrm{O}_{2}\left(\mathrm{~N}_{2}\right)$, and (d) $\mathrm{MoV}-\mathrm{N}_{2}\left(\mathrm{~N}_{2}\right)$.

[36]. As the $\mathrm{Mo}^{6+}$ cation has a similar size as $\mathrm{V}^{4+}$, it has an important role in accommodating vanadium atoms in the lattice, and consequently in improving the dynamic change of the vanadium oxidation state and the creation of oxygen vacancies during the catalytic steps.

Fig. 6 shows the catalytic results for the samples under a flow of $100 \% \mathrm{O}_{2}$ at $320^{\circ} \mathrm{C}$ in a $6 \mathrm{~h}$ reaction. As previously, there was enhancement of both the selectivity towards acrylic acid and glycerol conversion, while the samples calcined in an inert atmosphere showed the poorest results. Table S1 shows the conversion and selectivities to the catalysts after $6 \mathrm{~h}$ on stream. The quantity of other products formed during the reaction (acetol, propanal, allyl alcohol, 3-hydroxypropanal and propionic acid) was less than $4 \%$, for that reason these products are not represented in Fig. 6.

\subsection{Post-reaction characteristics}

After the $6 \mathrm{~h}$ catalytic tests at $320{ }^{\circ} \mathrm{C}$ under a flow of $20 \% \mathrm{O}_{2}$ in $\mathrm{N}_{2}$, a post-reaction investigation of the spent samples was performed using thermogravimetric measurements, Rietveld refinement of the X-ray diffraction patterns, TPD- $\mathrm{NH}_{3}$ and $\mathrm{X}$-ray absorption near vanadium $\mathrm{K}$ edge spectroscopy. Measurements were also performed for the MoV$\mathrm{O}_{2}\left(\mathrm{O}_{2}\right)$ sample after a $6 \mathrm{~h}$ reaction at $320{ }^{\circ} \mathrm{C}$ under $100 \% \mathrm{O}_{2}$ (this sample was denoted $\left.\mathrm{MoV}-\mathrm{O}_{2}\left(\mathrm{O}_{2}\right)-100 \% \mathrm{O}_{2}\right)$. The Rietveld refinement results are shown in Table 4 and Fig. S4. All the samples formed the same families of crystallographic phases $\left(\mathrm{MoVO}_{5}, \mathrm{Mo}_{4.65} \mathrm{~V}_{0.35} \mathrm{O}_{14}\right.$, and $\mathrm{MoO}_{3}$ ), due to structural reorganization of the mixed oxides under the glycerol flow. The catalysts that were previously heat-treated in an oxidizing atmosphere contained mainly the $\mathrm{Mo}_{4.65} \mathrm{~V}_{0.35} \mathrm{O}_{14}$ phase, with a smaller quantity of $\mathrm{MoVO}_{5}$. This behavior was the opposite of that observed for the catalysts heat-treated in an inert atmosphere, which presented mainly the $\mathrm{MoVO}_{5}$ phase. For the $\mathrm{MoV}-\mathrm{O}_{2}\left(\mathrm{O}_{2}\right)$ catalyst that was submitted to a flow of $100 \% \mathrm{O}_{2}$, the quantitative crystallographic phase analysis revealed $44.3 \%$ of $\mathrm{MoVO}_{5}$ and $35.6 \%$ of $\mathrm{Mo}_{4.65} \mathrm{~V}_{0.35} \mathrm{O}_{14}$. The performance of the samples showed a correlation with the $\mathrm{MoVO}_{5} /$ $\mathrm{Mo}_{4.65} \mathrm{~V}_{0.35} \mathrm{O}_{14}$ molar ratio, as depicted in Fig. 7. The highest selectivity towards acrylic acid was achieved at a ratio between the two phases of about 1 .

The elemental analysis found negligible amounts of carbon and hydrogen in the samples, evidencing that coke was not formed in the catalysts. The thermogravimetric analysis of the spent catalysts (Fig. 8) showed that all the catalysts presented a weight loss in the $100-200{ }^{\circ} \mathrm{C}$ range, corresponding to elimination of physisorbed water, and then a weight gain at temperatures above $300{ }^{\circ} \mathrm{C}$, due to the reoxidation of $\mathrm{V}^{4+}$ to $\mathrm{V}^{5+}$. Therefore, the temperature at which the oxidation started was very important, because it determined the ease with which the active redox sites were restored. The catalysts heat-treated in $\mathrm{N}_{2}$ presented higher reoxidation temperatures (above $350^{\circ} \mathrm{C}$ ), compared to the catalysts heat-treated in $\mathrm{O}_{2}$ (reoxidation temperatures below $320^{\circ} \mathrm{C}$ ).

The X-ray absorption near vanadium K-edge spectroscopy (XANES region) results for the as-synthesized and spent catalysts are shown in Fig. 9. The linear combination fittings of the XANES spectra were performed using $\mathrm{V}_{2} \mathrm{O}_{5}, \mathrm{~V}_{2} \mathrm{O}_{4}$, and $\mathrm{V}_{2} \mathrm{O}_{3}$ spectra as references (Fig. S5) and showed increased amounts of $\mathrm{V}^{4+}$ for all the spent catalysts, compared to the fresh ones (Table 4 and Fig. 9). The spent MoV- $\mathrm{N}_{2}\left(\mathrm{~N}_{2}\right)$ $20 \%$, MoV- $\mathrm{N}_{2}\left(\mathrm{O}_{2}\right)-20 \%$, and MoV- $\mathrm{O}_{2}\left(\mathrm{~N}_{2}\right)-20 \%$ catalysts presented the 
Table 4

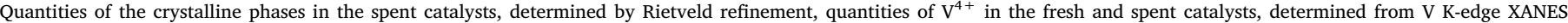
measurements, and yields of acrylic acid after $6 \mathrm{~h}$ of reaction.

\begin{tabular}{|c|c|c|c|c|c|c|}
\hline \multirow[t]{2}{*}{ Spent catalyst } & \multicolumn{3}{|c|}{ Phase content (\%) } & \multirow[t]{2}{*}{$\mathrm{V}^{4+}$ in the fresh catalysts (\%) } & \multirow[t]{2}{*}{$\mathrm{V}^{4+}$ in the spent catalysts (\%) } & \multirow[t]{2}{*}{ Yield of acrylic acid after $6 \mathrm{~h}(\%)$} \\
\hline & $\mathrm{MoVO}_{5}$ & $\mathrm{Mo}_{4.65} \mathrm{~V}_{0.35} \mathrm{O}_{14}$ & $\mathrm{MoO}_{3}$ & & & \\
\hline MoV-O ${ }_{2}\left(\mathrm{O}_{2}\right)-100 \% \mathrm{O}_{2}$ & 37.8 & 35.1 & 27.1 & 36 & 43 & 29.6 \\
\hline $\mathrm{MoV}-\mathrm{O}_{2}\left(\mathrm{O}_{2}\right)-20 \% \mathrm{O}_{2}$ & 38.3 & 49.4 & 12.3 & 36 & 57 & 22.9 \\
\hline MoV-N $\mathrm{N}_{2}\left(\mathrm{O}_{2}\right)-20 \% \mathrm{O}_{2}$ & 30.9 & 61.6 & 7.5 & 58 & 89 & 9.8 \\
\hline MoV-O $\left(\mathrm{N}_{2}\right)-20 \% \mathrm{O}_{2}$ & 71.1 & 27.0 & 1.9 & 55 & 80 & 10.3 \\
\hline MoV- $\mathrm{N}_{2}\left(\mathrm{~N}_{2}\right)-20 \% \mathrm{O}_{2}$ & 55.6 & 21.0 & 23.4 & $18\left(82 \%\right.$ of $\left.\mathrm{V}^{3+}\right)$ & 70 & 11.3 \\
\hline
\end{tabular}

Reaction conditions: $320^{\circ} \mathrm{C}$ and $20 \% \mathrm{O}_{2}$ or $100 \% \mathrm{O}_{2}$ as the gas flow.

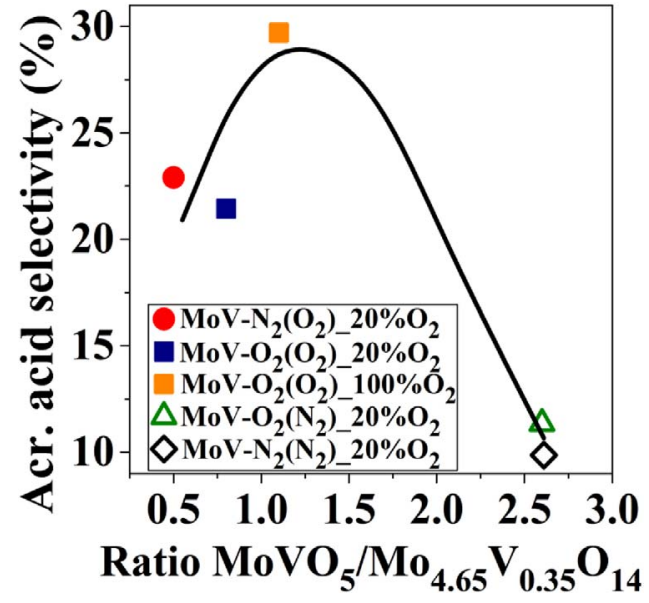

Fig. 7. Correlation between the acrylic acid selectivity in the last hour of the reaction and the ratio of the crystallographic phases $\left(\mathrm{MoVO}_{5} / \mathrm{Mo}_{4.65} \mathrm{~V}_{0.35} \mathrm{O}_{14}\right)$ found for the spent catalysts.

highest quantities of $\mathrm{V}^{4+}$. Curiously, among all the catalysts, these materials had the worst yield towards acrylic acid in the last hour of the reaction. The spent $\mathrm{MoV}-\mathrm{O}_{2}\left(\mathrm{O}_{2}\right)-20 \%$ and $\mathrm{MoV}-\mathrm{O}_{2}\left(\mathrm{O}_{2}\right)-100 \%$ catalysts showed lower quantities of $\mathrm{V}^{4+}$, with values of $57 \%$ and $43 \%$, respectively, and higher yield towards acrylic acid in the last hour of the reaction, as shown in Table 3.

Temperature programed desorption of ammonium of the spent catalyst $\mathrm{MoV}-\mathrm{O}_{2}\left(\mathrm{O}_{2}\right)-100 \%$ was conducted to observe any changes in the acidity comparing with the fresh catalyst $\mathrm{MoV}-\mathrm{O}_{2}\left(\mathrm{O}_{2}\right)$. The results in Fig. 10 shows that the total acids sites of the spent catalyst decreases compared to the fresh one, 21.9 and $38.9 \mu \mathrm{mol} / \mathrm{g}$, respectively.

\section{Discussion}

By means of in situ X-ray diffraction patterns, it was possible to follow the formation of diverse crystalline phases of mixed oxides, which were dependent on the atmospheres used during synthesis and calcination. Fig. 3 indicates that the presence of mixed oxide phases is more abundant in the catalysts treated in oxygen atmosphere (synthesis or calcination). This is coherent when we compare the oxidation states of vanadium in precursor salt, $\mathrm{VOSO}_{4}\left(\mathrm{~V}^{4+}\right)$, and in the formed mixed oxide phases, where, basically, all of them presents vanadium in high oxidation states. The sample synthesized in oxygen atmosphere, which presents approximately $70 \%$ of the mixed oxide phase $\mathrm{Mo}_{0.88} \mathrm{~V}_{0.12} \mathrm{O}_{2.94}$, when calcined in oxidant or inert atmosphere, despite undergoing a phase restructuring, tends to preserve a high amount of mixed oxide phases. When synthesized in nitrogen atmosphere, after calcination in oxidant atmosphere the sample show the formation of $\mathrm{Mo}_{4.65} \mathrm{~V}_{0.35} \mathrm{O}_{14}$ and $\mathrm{MoV}_{2} \mathrm{O}_{8}$ mixed oxide phases, but a considerable quantity of $\mathrm{MoO}_{3}$ phase is present in the material. After calcination in inert atmosphere this sample present just pure oxides phases with vanadium and molybdenum in reduced forms. The mixed phases observed in this work are, basically, formed by incorporation of vanadium atoms in the structure of molybdenum oxides and, comparing these results can be noted that, in the mild conditions of synthesis proposed in this work, the vanadium in high oxidation states, that possess a smaller ionic radius compared do reduced forms of vanadium, like $\mathrm{V}^{4+}$, can easily be introduced and accommodated in molybdenum oxide structures. The oxidant atmosphere plays an important role so that structures of mixed oxides with reduced forms of vanadium, like $\mathrm{MoVO}_{5}$, are not preferen-

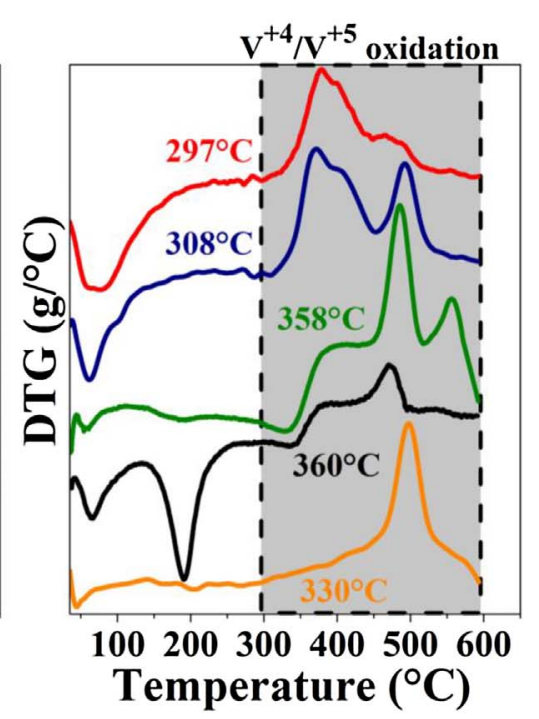

Fig. 8. Thermogravimetric and derivative analysis curves for the spent catalysts. 


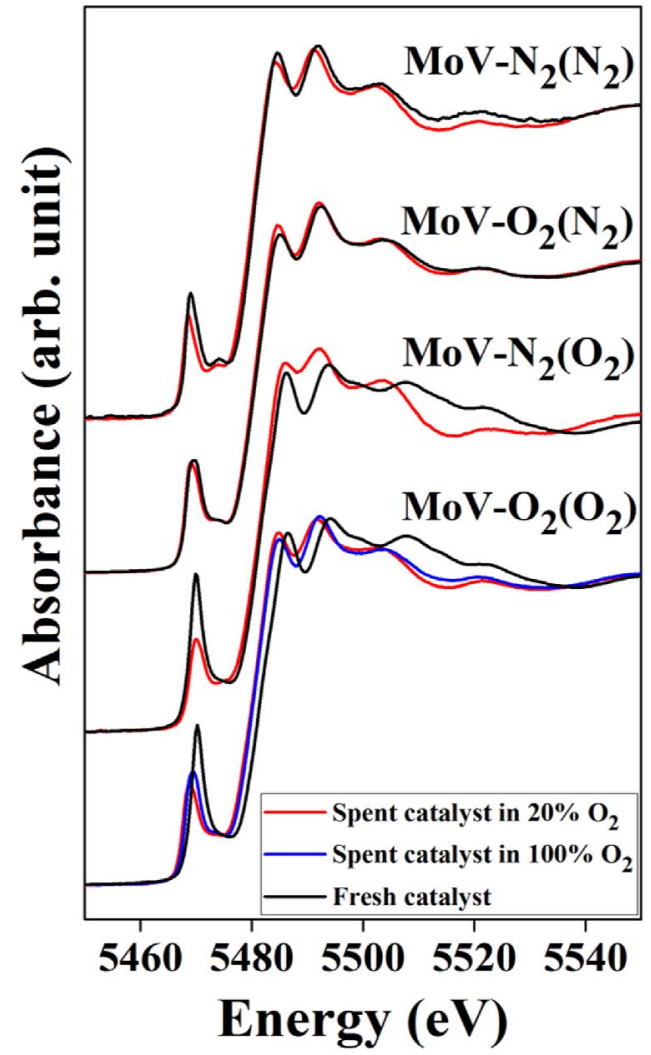

Fig. 9. X-ray absorption near vanadium K-edge spectroscopy for the mixed oxides of molybdenum and vanadium.

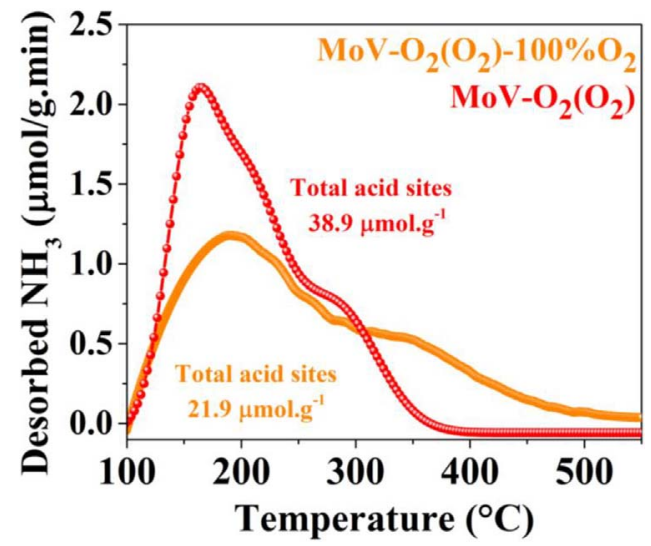

Fig. 10. Temperature programmed desorption of ammonia for the fresh and spent catalyst $\mathrm{MoV}-\mathrm{O}_{2}\left(\mathrm{O}_{2}\right)$.

tially formed when an inert atmosphere is used. Due to the varied phase composition, it was not possible to establish a straightforward relationship between the structure of the mixed oxide and the catalytic activity. However, the most active catalysts, calcined in oxygen, presented approximately $45 \%$ of the $\mathrm{Mo}_{4.65} \mathrm{~V}_{0.35} \mathrm{O}_{14}$ crystalline phase, which was absent in the catalysts calcined in nitrogen. Formation of the $\mathrm{Mo}_{4.65} \mathrm{~V}_{0.35} \mathrm{O}_{14}$ crystalline phase was observed elsewhere in $\mathrm{MoV} / \mathrm{SiW} /$ $\mathrm{Al}_{2} \mathrm{O}_{3}$ catalyst synthesis and was identified as the most active phase in the oxidation of acrolein to acrylic acid [16].

Although the catalysts did not possess high quantities of total acid sites, medium and strong acid sites were present, notably in the samples calcined in oxygen ( $>50 \%$ ), which could be beneficial in the dehydration step. Several studies have shown that adequate strength of the acid sites is important because the adsorption of glycerol on relatively moderate strength acid sites favors the production of 3-hydroxypropa- nal, which consequently dehydrates to acrolein [41,42]. In the glycerol oxydehydration, the formation of $\mathrm{CO}$ and $\mathrm{CO}_{2}$ is commonly associated with $(\mathrm{Mo}, \mathrm{V}) \mathrm{O}_{\mathrm{X}}$ species, the pure oxide phases, that promote complete oxidation of intermediates such as acetol, 3-hydroxypropane, and acrylic acid $[16,45]$.

For all the samples, the change of the gas flow composition to $100 \%$ $\mathrm{O}_{2}$ caused increases in the conversion of glycerol and the selectivity towards acrylic acid. The use of pure $\mathrm{O}_{2}$ enabled more effective reestablishment of the oxygen vacancies, previously described in the Mars-van-Krevelen oxidation mechanism. The active sites of the catalyst were therefore maintained and were readily available to oxidize acrolein, besides inhibiting the deposition of coke [43-47]. However, the excess of molecular oxygen alone was not sufficient to explain the increase in catalytic performance. In a previous study, Wang et al. [48] reported a high selectivity towards acrolein, with low formation of acrylic acid, in the glycerol reaction over vanadium-based catalysts, with a gas flow rich in $\mathrm{O}_{2}$. Hence, the role of the structure and composition of the mixed oxides in directing the reaction to certain products is clearly important.

The starting composition of the mixed oxides in the fresh catalysts is another important point to be highlighted, because it determined the structural reorganization of the phases during the reaction and the capacity for changes in the $\mathrm{V}^{4+} / \mathrm{V}^{5+}$ oxidation states, as measured by $\mathrm{X}$-ray absorption near vanadium K-edge spectroscopy. In the course of the reaction, the catalysts were restructured, with the $\mathrm{Mo}_{4.65} \mathrm{~V}_{0.35} \mathrm{O}_{14}$, $\mathrm{MoVO}_{5}$, and $\mathrm{MoO}_{3}$ phases being observed in all cases (Fig. S4). However, the spent catalysts showed different equilibria between the phases (Table 4).

Both acid and redox active sites are necessary to accomplish the oxydehydration of glycerol, but acrylic acid production seems to depend mainly on the establishment of a suitable equilibrium of the reduced and oxidized phases (Fig. 7). Maximum productivity was achieved with a ratio between the phases of about 1 . The XANES measurements (Table 4, Fig. 9) showed that when treated using a gas flow of $100 \% \mathrm{O}_{2}$ at $320{ }^{\circ} \mathrm{C}$, the MoV- $\mathrm{O}_{2}\left(\mathrm{O}_{2}\right)$ catalyst presented $43 \%$ of $\mathrm{V}^{4+}$. Although this catalyst contained a lower amount of $\mathrm{V}^{4+}$, compared to the other catalysts, it provided the highest selectivity towards acrylic acid. These results suggest that $\mathrm{V}^{4+}$ in excess did not benefit the formation of acrylic acid. Nonetheless, equilibrium between $\mathrm{V}^{4+}$ and $\mathrm{V}^{5+}$ seemed to be necessary. It has been reported that the presence of $\mathrm{V}^{4+}$ stabilizes the intermediate acrylate ion and that if acrylate adsorption is impaired, it could be further oxidized to $\mathrm{CO}_{2}$ $[49,50]$.

The thermogravimetric analysis of the spent catalysts (Fig. 8) revealed differences in the initial temperature of reoxidation between the catalysts heat-treated in $\mathrm{O}_{2}$ and $\mathrm{N}_{2}$. For the catalysts heat-treated in an inert atmosphere, the oxidation of $\mathrm{V}^{4+}$ to $\mathrm{V}^{5+}$ began at a higher temperature than the reaction temperature $\left(320^{\circ} \mathrm{C}\right)$, which must have been associated with the higher quantity of the reduced $\mathrm{MoVO}_{5}$ phase. For the spent $\mathrm{MoV}-\mathrm{O}_{2}\left(\mathrm{O}_{2}\right)-20 \%$ and $\mathrm{MoV}-\mathrm{N}_{2}\left(\mathrm{O}_{2}\right)-20 \%$ catalysts, the temperature of re-oxidation was significantly lower than the reaction temperature, favoring the oxidation of $\mathrm{V}^{4+}-\mathrm{V}^{5+}$, associated with greater formation of the oxidized $\mathrm{Mo}_{4.65} \mathrm{~V}_{0.35} \mathrm{O}_{14}$ phase. The spent MoV- $\mathrm{O}_{2}\left(\mathrm{O}_{2}\right)-100 \%$ catalyst presented a reoxidation temperature close to the reaction temperature, which could explain the similar quantities of the reduced and oxidized phases.

The TPD- $\mathrm{NH}_{3}$ analysis of the fresh and spent catalyst $\mathrm{MoV}-\mathrm{O}_{2}\left(\mathrm{O}_{2}\right)$ (Fig. 10) unveil that the acidity after the 6-h reaction decreases, the total amount of acid sites went from 38.9 to $21.9 \mu \mathrm{mol} \mathrm{NH} \mathrm{N}_{3} \cdot \mathrm{g}^{-1}$. This is expected because in XANES measurements the quantity of $\mathrm{V}^{+4}$ increased in the spent catalyst comparing to the fresh one. More $\mathrm{V}^{+4}$ leads to a decrease of the acidity of the catalyst. According to Possato et al. [36] and Takita et al. [51] the reason to the reduction of acid sites is the influence of the water vapor during the reaction, where the water molecule can dissociate in the surface of the catalyst making more oxygen available for the reaction, what reduces the $\mathrm{V}^{+5}$ sites and 
Table 5

Comparison of glycerol oxydehydration into acrylic acid, glycerol conversion and $\mathrm{CO}_{\mathrm{x}}$ selectivity with different heterogeneous catalysts in the literature.

\begin{tabular}{|c|c|c|c|c|}
\hline Catalyst & $\begin{array}{l}\text { Glycerol } \\
\text { conversion } \\
(\%)\end{array}$ & $\begin{array}{l}\text { Acr. acid } \\
\text { selectivity } \\
(\%)\end{array}$ & $\begin{array}{l}\mathrm{CO}_{\mathrm{X}} \\
\text { selectivity } \\
(\%)\end{array}$ & Ref. \\
\hline $\mathrm{MoV} / \mathrm{SiW} / \mathrm{Al}_{2} \mathrm{O}_{3}$ & 100 & 12 & 55.6 & [16] \\
\hline $\mathrm{V}_{2} \mathrm{O}_{5}-\mathrm{MFI}$ & 100 & 17 & $>60$ & [15] \\
\hline Mo-V-O & 95 & 20.1 & 40 & [30] \\
\hline W_V-O & 100 & 23.7 & 54.7 & [19] \\
\hline W-V-O & 100 & 26 & 47 & [20] \\
\hline Mo-V-O & 100 & 26.3 & 35.1 & [19] \\
\hline Mo-V-Te-Nb-O & 99.6 & 28.4 & 44.8 & [19] \\
\hline Mo-V-O & 94 & 32 & 20 & [36] \\
\hline W-V-Nb-O & 100 & 33.7 & 42.7 & [34] \\
\hline W-V-Nb-O & 100 & 51 & 35 & [18] \\
\hline $2.5 \mathrm{wt} \% \mathrm{PO}_{4} / \mathrm{W}_{2.2} \mathrm{~V}_{0.4} \mathrm{Nb}_{2.4} \mathrm{O}_{14}$ & 100 & 59.2 & 22.3 & [34] \\
\hline $\mathrm{Cs}(\mathrm{VO})_{0.2}(\mathrm{PMo})_{0.5}(\mathrm{PW})_{0.5}$ & 100 & 60 & 13.2 & [33] \\
\hline Vanadosilicate & 93.6 & 85.4 & 10 & [43] \\
\hline Mo-V-O & 100 & 33.5 & 59 & $\begin{array}{l}\text { This } \\
\text { work }\end{array}$ \\
\hline
\end{tabular}

decrease the catalyst acidity.

Table 5 shows a comparison of this work with others in the literature for the glycerol oxydehydration to acrylic acid using solid acid catalysts. Unfortunately, all the catalysts independent of the reaction condition (temperature or reaction gas composition), presented a high formation of $\mathrm{CO}_{\mathrm{X}}$ up to $50 \%$ and it is believed that is due to the decomposition of glycerol and the formed products, what is inevitable as reported in several studies. Although $\mathrm{CO}_{\mathrm{X}}$ formation for our best catalysts is high (around 60\%), acrylic acid was the most abundant condensable product $(33.5 \%)$ with a low formation of minor products $(<4 \%)$ and a $100 \%$ conversion, not presenting deactivation after $6 \mathrm{~h}$. Possato et al. [36] in his work showed a Mo-V-O based catalysts for the glycerol oxydehydration to acrylic acid with $32 \%$ of selectivity to acrylic acid and $20 \%$ of $\mathrm{CO}_{\mathrm{x}}$ selectivity, however the catalyst deactivates and in the eighth hour the acrylic acid selectivity achieves around $5 \%$ and $\mathrm{CO}_{\mathrm{X}}$ selectivity $80 \%$.

\section{Conclusions}

Mixed oxides of vanadium and molybdenum were prepared by a hydrothermal synthesis procedure and were heat-treated in different atmospheres. A correspondence was observed between the structural compositions of the catalysts formed and their catalytic behavior in the one-step oxydehydration of glycerol to acrylic acid. The catalysts heattreated in an oxidizing atmosphere showed the best catalytic performance in terms of selectivity towards acrylic acid. Reactions carried out at $320{ }^{\circ} \mathrm{C}$, with a gas flow composed of $100 \% \mathrm{O}_{2}$, were found to give the highest selectivity towards acrylic acid and the best long-term catalyst stability and the catalysts heat-treated in oxygen presented the best selectivities, achieving $33.5 \%$ of acrylic acid. The explanation for this was that a gas flow rich in $\mathrm{O}_{2}$ resulted in a suitable equilibrium in the formation of phases of mixed oxides containing $\mathrm{V}^{4+}$ and $\mathrm{V}^{5+}\left(\mathrm{MoVO}_{5}\right.$ and $\mathrm{Mo}_{4.65} \mathrm{~V}_{0.35} \mathrm{O}_{14}$, respectively). The evidence obtained in this study concerning the different phases of mixed oxides and the performance of the catalysts in the glycerol oxydehydration highlights the importance of controlling the synthesis and calcination atmospheres.

\section{Acknowledgements}

This work was supported by the Brazilian agencies CNPq (152447/ 2015-6), CNPq/PVE (401679/2013-6), and FAPESP (2014/20116-6 and 2016/10597-2). The authors also thank the Brazilian Synchrotron Light Laboratory (LNLS) in Campinas for use of the XPD (proposals
XPD-18893 and XPD-20150244) and XAFS 1 (20160929) beamlines.

\section{Appendix A. Supplementary data}

Supplementary data associated with this article can be found, in the online version, at http://dx.doi.org/10.1016/j.cattod.2017.04.006.

\section{References}

[1] S. Marx, Fuel Process. Technol. 151 (2016) 139-147.

[2] M.R. Nanda, Z. Yuan, W. Qin, C.C. Xu, Catal. Rev. Sci. Eng. 58 (3) (2016) 309-336.

[3] M.R. Nanda, Y. Zhang, Z. Yuan, W. Qin, H.S. Ghaziaskar, C. Xu, Renew. Sustain. Energy Rev. 56 (2016) 1022-1031.

[4] R. Estevez, S. Lopez-Pedrajas, F. Blanco-Bonilla, D. Luna, F.M. Bautista, Chem. Eng. J. 282 (2015) 179-186.

[5] V.K. Garlapati, U. Shankar, A. Budhiraja, Biotechnol. Rep. 9 (2016) 9-14.

[6] S. Lemos, J. Soares, L. Pires, Quim. Nov. 33 (2010) 1682-1685.

[7] B. Katryniok, S. Paul, F. Dumeignil, ACS Catal. 3 (2013) 1819-1834.

[8] A. Talebian-Kiakalaieh, N.A.S. Amin, H. Hezaveh, Renew. Sustain. Energy Rev. 40 (2014) $28-59$.

[9] A. Talebian-Kiakalaieh, N.A.S. Amin, Z.Y. Zakaria, J. Ind. Eng. Chem. 34 (2016) 300-312.

[10] A. Chieregato, F. Basile, P. Concepción, S. Guidetti, G. Liosi, M.D. Soriano, C. Trevisanut, F. Cavani, J.M. López Nieto, Catal. Today 197 (2012) 58-65.

[11] S. Thanasilp, J.W. Schwank, V. Meeyoo, S. Pengpanich, M. Hunsom, J. Mol. Catal. A Chem. 380 (2013) 49-56.

[12] J.-L. Dubois, C. Duquenne, W. Holderich, Method for producing acrylic acid from glycerol, US 7,910,771 B2, (2011).

[13] J.-L. Dubois, G. Patience, Method for preparing acrylic acid from glycerol, US 8,212,070 B2, (2012).

[14] A. Chieregato, M.D. Soriano, F. Basile, G. Liosi, S. Zamora, P. Concepción, F. Cavani, J.M. López Nieto, Appl. Catal. B Environ. 150-151 (2014) 37-46.

[15] L.G. Possato, W.H. Cassinelli, T. Garetto, S.H. Pulcinelli, C.V. Santilli, L. Martins, Appl. Catal. A Gen. 492 (2015) 243-251.

[16] L. Liu, B. Wang, Y. Du, Z. Zhong, A. Borgna, Appl. Catal. B Environ. 174-175 (2015) 1-12.

[17] Y.S. Yun, K.R. Lee, H. Park, T.Y. Kim, D. Yun, J.W. Han, J. Yi, ACS Catal. 5 (2014) 82-94.

[18] A. Chieregato, M.D. Soriano, E. García González, G. Puglia, F. Basile, P. Concepción, C. Bandinelli, J.M. López Nieto, F. Cavani, ChemSusChem 8 (2015) 398-406.

[19] J. Deleplanque, J.L. Dubois, J.F. Devaux, W. Ueda, Catal. Today 157 (2010) 351-358.

[20] M.D. Soriano, P. Concepción, J.M.L. Nieto, F. Cavani, S. Guidetti, C. Trevisanut, Green Chem. 13 (2011) 2954-2962.

[21] A. Witsuthammakul, T. Sooknoi, Appl. Catal. A Gen. 413-414 (2012) 109-116.

[22] G. Centi, S. Perathoner, Compr. Inorg. Chem. II, (2013), pp. 153-184.

[23] S. Ishikawa, X. Yi, T. Murayama, W. Ueda, Appl. Catal. A Gen. 474 (2014) 10-17.

[24] S. Ishikawa, D. Kobayashi, T. Konya, S. Ohmura, T. Murayama, N. Yasuda, M. Sadakane, W. Ueda, J. Phys. Chem. C 119 (2015) 7195-7206.

[25] B. Chu, L. Truter, T.A. Nijhuis, Y. Cheng, Appl. Catal. A Gen. 498 (2015) 99-106.

[26] S. Ishikawa, W. Ueda, Catal. Sci. Technol. 6 (2016) 617-629.

[27] T. Katou, D. Vitry, W. Ueda, Chem. Lett. 32 (2003) 1028-1029.

[28] W. Ueda, D. Vitry, T. Katou, Catal. Today 99 (2005) 43-49.

[29] Y. Choi, H. Park, Y.S. Yun, J. Yi, ChemSusChem 8 (2015) 974-979.

[30] L. Shen, H. Yin, A. Wang, X. Lu, C. Zhang, Chem. Eng. J. 244 (2014) 168-177.

[31] L. Shen, H. Yin, A. Wang, Y. Feng, Y. Shen, Z. Wu, T. Jiang, Chem. Eng. J. 180 (2012) 277-283.

[32] L. Shen, H. Yin, A. Wang, X. Lu, C. Zhang, F. Chen, Y. Wang, H. Chen, J. Ind. Eng. Chem. 20 (2014) 759-766.

[33] X. Li, Y. Zhang, ACS Catal. 6 (5) (2016) 2785-2791.

[34] K. Omata, K. Matsumoto, T. Murayama, W. Ueda, Catal. Today 259 (2016) 205-212.

[35] E.M. Thorsteinson, T.P. Wilson, F.G. Young, P.H. Kasai, J. Catal. 52 (1978) 116-132.

[36] L.G. Possato, W.H. Cassinelli, C.I. Meyer, T. Garetto, S.H. Pulcinelli, C.V. Santilli, L. Martins, Appl. Catal. A Gen. 532 (2017) 1-11.

[37] G. Leofanti, M. Padovan, G. Tozzola, B. Venturelli, Catal. Today 41 (1998) 207-219.

[38] W. Suprun, M. Lutecki, T. Haber, H. Papp, J. Mol. Catal. A Chem. 309 (2009) 71-78.

[39] S. Ishikawa, X. Yi, T. Murayama, W. Ueda, Catal. Today 238 (2014) 35-40.

[40] M. Sadakane, N. Watanabe, T. Katou, Y. Nodasaka, W. Ueda, Angew. Chem. Int. Ed. 46 (2007) 1493-1496.

[41] S. Ishikawa, M. Tashiro, T. Murayama, W. Ueda, Cryst. Growth Des. 14 (2014) 4553-4561.

[42] C. Chiu, T. Vogt, L. Zhao, A. Genest, N. Rösch, Dalton Trans. 44 (2015) 13778-13795.

[43] A. Silva Paula, L.G. Possato, D. Ratero, J. Contro, K. Keinan-Adamsky, R. Soares, G. Goobes, L. Martins, J.G. Nery, Microporous Mesoporous Mat. 232 (2016) 151-160.

[44] L.H. Vieira, K.T.G. Carvalho, E.A. Urquieta-González, S.H. Pulcinelli, C.V. Santilli, L. Martins, J. Mol. Catal. A Chem. 422 (2015) 148-157.

[45] T. Ressler, A. Walter, Z. Huang, W. Bensch, J. Catal. 254 (2008) 170-179.

[46] J. Tichý, Appl. Catal. A Gen. 157 (1997) 363-385.

[47] L. Giebeler, P. Kampe, A. Wirth, A.H. Adams, J. Kunert, H. Fuess, H. Vogel, J. Mol. Catal. A Chem. 259 (2006) 309-318.

[48] F. Wang, J. Dubois, W. Ueda, J. Catal. 268 (2009) 260-267.

[49] T.G. Kuznetsova, G.K. Boreskov, T.V. Andrusttkevich, Y.A. Grigorkina, N.G. Maksimov, I.P. Olenkova, L.M. Plyasova, T.P. Gorshkova, Catal. Lett. 19 (1982) 405-409.

[50] T.G. Kuznetsova, G.K. Boreskov, T.V. Andrushkevich, L.M. Plyasova, N.G. Maksimov, I.P. Olenkova, Catal. Lett. 12 (1979) 531-536.

[51] Y. Takita, J. Catal. 1 (1978) 95-101. 